Title:

In press with:

Authors:

Affiliation:

Email:

Telephone:

Fax:
Complex caring trajectories in community mental health: contingencies,

divisions of labor and care coordination

Community Mental Health Journal

Ben Hannigan, Davina Allen

Cardiff School of Nursing and Midwifery Studies, Cardiff University, Eastgate House, 35-43 Newport Road, Cardiff, CF24 0AB, UK

\section{Ben Hannigan}

hanniganb@cardiff.ac.uk

$+44(0) 2920917726$

$+44(0) 2920917715$ 


\title{
Complex caring trajectories in community mental health: contingencies, divisions of labor and care coordination
}

\begin{abstract}
The concept of 'trajectory' refers to the unfolding of individual service users' health and illness experiences, the organization of health and social care work surrounding them and the impact this work has on people involved. Using qualitative data from a study completed in two sites in Wales we first reveal the complex character of trajectories encountered in the community mental health field. We show how these can be shaped by features peculiar to mental ill-health per se, and by features with organizational origins. We then use our data to lay bare true divisions of labor. Mental health professionals featured prominently in our study. We also reveal relatively invisible contributions made by professionals on the periphery, support workers, unpaid lay carers and service users. In examining the significance of our findings we identify particular lessons for mental health practitioners, managers and policymakers sharing concerns for the coordination of care.
\end{abstract}

\section{Keywords}

care coordination; mental health systems; roles; trajectories; UK; work. 


\section{Introduction}

The concept of 'trajectory' refers to the unfolding of individual service users' health and illness experiences, the organization of health and social care work surrounding them and the impact this work has on all involved (Strauss et al. 1985). In this paper we demonstrate how the study of trajectories enables the day-to-day complexities of community mental health care to be laid bare. Examining mental health trajectories also reveals the full division of paid and unpaid work in this field. Using qualitative data generated across two contrasting sites in Wales, UK, we show the vulnerability of trajectories to being tilted by features characteristic of the mental ill-health experience per se, and by features with organizational origins. In each of the individual trajectories we studied, roles were fulfilled by representatives of 'usual suspect' mental health professional groups (including nurses, psychiatrists, and social workers). Our data also reveal important, but relatively invisible, work being done by professionals located on the periphery, by support workers, and by unpaid lay carers and service users themselves. We examine the significance of these findings in the context of care coordination, identifying lessons for mental health practitioners and others concerned with the organization and delivery of services at the individual level.

Writing initially for a medical sociology audience, in Social Organization of Medical Work Strauss et al. (1985) remark how little of what passes for the study of work focuses directly on work itself. They argue that investigations more commonly take as their starting point the roles of designated professionals, inter-occupational relations or formal divisions of labor. With this observation in mind they introduce the concept of 'illness trajectories' to refer:

...not only to the physiological unfolding of a patient's disease but to the total organization of work done over that course, plus the impact on those involved with that work and its organization (Strauss et al. 1985: 8).

The concept of 'trajectory' is therefore far broader than the more limited term 'course of illness'. Researching trajectories means attending to user experiences, and to the entirety of the work which is done, rather than to the activities of members of one or more pre-defined groups. 'Workers' are thus brought into view through a primary focus on 'work' 
These foundational ideas remain insightful and important. Other aspects of Strauss et al.'s original exposition need modest revision to better reflect features of contemporary care systems. The term 'caring trajectory', coined by Allen et al. (2004) in preference to 'illness trajectory', more suitably reflects the combined health and social care contributions made in hospitals and in the community in cases of long-term ill-health. Strauss and his colleagues' relatively narrow preoccupation with work and physical illness is also suggested by their focus on the 'physiological unfolding of [...] disease'. The example of long-term mental health difficulties shows how health experiences also manifest in psychological and social ways, with important implications for work which needs to be done and for the fulfillment of roles.

No revisions are needed to Strauss et al.'s insights into the combinations of factors shaping trajectories, or to the idea that they are capable of unfolding in complex and unpredictable ways. All trajectories, including those which appear relatively routine from the perspective of involved professionals, have meaning and consequences for service users. Trajectories are also dynamic. As Strauss et al. (1985) suggest, this is because health care work is always 'people work'. 'People' in this context include nurses, doctors, therapists and others concerned with any given case. But service users do 'work' too, as do lay carers. Trajectory complexity is also magnified by what Strauss and his colleagues call 'contingencies', of which there are two principal types. First are those associated with the experience of chronic illness as such. Long-term ill-health is disruptive, and demands active management by those affected (Corbin and Strauss 1988). This has consequences for individuals (and their carers), and thus for the directions which trajectories take. Second are contingencies with organizational origins, which according to Strauss et al. include a multitude of people and systemrelated factors. Examples include the biographical aspects of individual workers, the formal structuring of services and the relative availability of resources. Although she does not explicitly cast her work within a trajectories framework, Hart's (2001) study of system induced setbacks in the case of stroke survivors illustrates how factors external to the experience of illness can shape trajectories in the way Strauss describes. Alone or in combination, health and system-related contingencies can make any trajectory spin, like a gyroscope, in unpredictable directions before being tilted back on course or even finishing 'with a total collapse of control' (Strauss et al. 1985: 20). 


\section{Methods}

With these ideas as part of our theoretical backdrop the larger study from which our data are drawn had the aim of investigating work and organization in community mental health care at a time of significant policy-driven change. Research access was granted to two locales in Wales, UK, each distinguished from the other by having its statutory mental health services provided by different National Health Service (NHS) and social care-providing local authority organizations. Applications were made in the required way for independent NHS research ethics committee approval (Hannigan and Allen 2003).

In each locale a research base was established in an interprofessional community team providing care to adults with mental health difficulties, with fieldwork conducted over 22 months. Background data on the local policy and organizational contexts in which face-to-face community mental health care was being delivered were generated through a combination of interviews, observations and documentary analysis. NHS and local authority workers in both locales, drawn from senior management to frontline community team positions, were purposively sampled and invited to participate in interviews. Interview schedules were designed to produce data on the local development of services, their current configuration, and workers' roles. Documents (such as operational policies) were located and treated as data, and everyday events (for example, referral meetings) were sampled and observed, and contemporaneous fieldnotes made.

Beginning with initial negotiations conducted with responsible practitioners, access in each site was secured to a sample of three individuals with personal experience of mental health difficulty ('Jim', 'Simon' and 'Lenny' in site 1, and 'Miriam', 'Kerry' and 'Jenny' in site 2). Using an approach earlier developed by Allen et al. (2004) in their study of the trajectories of people recovering from stroke, each individual consented to become the starting point for a prospective, in-depth, case study (Yin 2009). Ethnographic data relating to the unfolding of each of these caring trajectories were generated for a period of up to five months. Snowball sampling (Coleman 1958) was used to identify all those playing significant parts in care provision. All who were identified in this way (professionals, support workers, service users and lay carers) were invited to participate in interviews focusing on work and roles. Access was also sought to scheduled events, including home visits and interprofessional care planning meetings where work was likely to be reviewed and decisions made. Where possible these were observed, and audio-recordings and/or contemporaneous fieldnotes made. A 
final source of data to support the detailed mapping of each of these six trajectories were the written records maintained by paid health and social care staff involved in the provision of services.

The project's overall dataset was managed with the assistance of the qualitative data analysis software package Atlas.ti (Lewins and Silver 2007; Scientific Software Development 2009). All interviews were audio-recorded and transcribed in full, other than one in which handwritten notes were instead made at the request of a participant who did not wish to be recorded. Across all primary documents, pseudonyms for people and places were inserted at the earliest opportunity as part of the preparation of materials for analysis. Inductive and deductive codes were created and used to identify and link segments of data in a variety of meaningful ways. Codes were used, for example, to tag people, tasks and events in descriptive fashion, and also to categorize and associate portions of data in more abstract, analytic, ways (cf. Coffey and Atkinson 1996). Connections between codes were made with the help of Atlas.ti's search-and-retrieve and network view capabilities, and were undertaken to support both within-case (i.e., single trajectory) and across-case analyses (Ayres et al. 2003).

\section{Results}

Mental health trajectories: health-related and organizational contingencies

Our within-case analysis reveals the degree to which caring trajectories in the community mental health field, including those likely to be judged as routine from the viewpoint of professionals, are personintensive, in motion, and capable of being knocked off course. Mental health work is 'people work' par excellence, and in this context we reveal how the departure of staff can be a significant, system-related, source of disruption. We also demonstrate how trajectories can be tilted by health-related contingencies, including the episodic changes in thinking, feelings and behavior characteristically experienced by people with mental health difficulties (Perkins and Repper 1996). Further in our paper we are able to show how the capacity of contingencies to tip trajectories underpins the case for effective care coordination, or what Strauss et al. (1985) term 'articulation work'.

Mental health practitioners know from experience of the disruptive potential of mental illhealth, and in this study this was particularly revealed in the trajectories of Miriam, Lenny and Kerry. All three experienced crises during their participation, with personal consequences and implications for workers and their tasks. Miriam, for example, was prone to episodic, disabling, depression and auditory 
hallucinations and in the context of acute crises had two admissions to hospital. Lenny had difficulties which included heavy alcohol use, depression, self-harming behavior and a fraught relationship with his parents. He took an overdose and was briefly admitted to hospital. Kerry had harmed herself in the past, heard voices, and had diabetes. Her paid carers described her as a high-risk service user. During her participation one key, evolving, event became a particular focus for work: responding to Kerry’s repeated intention to kill herself during a period specified in the future. This was a constant source of concern to practitioners, with Kerry's use of insulin meaning that she had ready access to the means necessary to carry through her plans.

In these three cases, as in the three others where personal health-related contingencies were less obvious shapers of trajectory direction, system-level contingencies also exerted significant effects. In Miriam's case, the lack of availability of alternatives to inpatient admission for people experiencing crises made hospital the only option open to her and her network of carers. A lack of beds at the time of her second admission meant that she was admitted to an out-of-area ward where she, with her particular needs, was not personally known to nurses or doctors. This had consequences for the quality of her experience as an inpatient, as she herself described:

Researcher: What happened when you were in hospital?

Miriam: I'm a veggie and they kept feeding me up meat. They said, 'the last veggie's just gone'.

Researcher: What about the fact that you didn't know any of the doctors or the nurses on the ward, what impact did that have?

Miriam: Nothing much, they hardly spoke to me there [...]. (Interview, service user, PD72 ${ }^{1}$ ). Miriam's regular psychiatrist, to whose care Miriam returned once home, described how a (rare) lack of communication across the hospital and community components of the local system had limited her participation in the process of discharge planning:

\footnotetext{
${ }^{1}$ Where 'PD' refers to 'primary document', such as a single interview transcript.
} 
Psychiatrist: [...] there was some confusion and it went on for a couple of weeks, and in the middle of it the junior doctor continued on the ward looking after her, not apparently bringing it to the attention of anybody else, hadn't seen a consultant [a senior doctor] in three weeks.

Researcher: With the outcome being that after three or so weeks you received this phone call asking you to review Miriam because she's ready to be discharged, without you ever knowing that she'd been there in the first place? Is that an unusual situation?

Psychiatrist: Yes, it shouldn’t happen, it's a rarity. (Interview, psychiatrist, PD78).

The trajectories of Lenny and Kerry, and Jenny's whose trajectory was otherwise relatively stable during her participation in the study, were all tilted by the departure from their posts of key members of their networks of care. In Lenny's case, his overdose coincided with the period after the departure of his social worker and before the arrival of a replacement. Kerry's nurse spoke of her impending move:

Researcher: Does Kerry know that you're leaving?

Community nurse: No, not yet. I've got to give eight weeks' notice. So it'll be a long time. It'll probably be just before she kills herself, so, and it's awful, it's going to be awful in a way because, I mean, that's a real predictor isn't it, suicide, you get used to like, key people, and when somebody gets very desperate or whatever and somebody's not there then that's another, so I don’t know [...] (Interview, community nurse, PD73).

In this case, then, Kerry's outgoing community nurse was clearly aware of the trajectory-changing potential her plans represented. In the event, and following this nurse's transfer to another team for promotion, Kerry was supported past her threatened suicide date without taking her life.

Usual suspects and invisible workers

The formal division of paid community mental health labor in the UK is complex, drawing in members of multiple professions: nurses, psychiatrists, social workers, occupational therapists, clinical psychologists and others (Hannigan and Allen 2006). Amongst investigations conducted into the work of these 'usual suspects' are projects focusing exclusively on the roles and identities of single groups 
(see for example: Sladden 1979; Pollock 1989; Bowers 1992; Godin 1996; Morrall 1997; Crawford et al. 2008), and projects involving representatives of different occupations (see for example: Wooff et al. 1988; Wooff and Goldberg 1988; Sheppard 1991; Norman and Peck 1999; Peck and Norman 1999; Brown et al. 2000; Stark et al. 2002; Brown and Crawford 2003; Hannigan and Allen 2011). In comparison, far less time has been spent investigating roles fulfilled by other, less visible, workers. Our approach to the mapping of trajectories made no a priori assumptions about which occupational groups should be examined, and in our analysis here we are able to reveal contributions made by professionals dispersed throughout larger systems of health and social care, by support workers, and indeed by mental health service users themselves and their unpaid, informal, carers. These findings add weight to our emphasis, made further in this paper, on the importance of work being pulled together through processes of care coordination.

\section{Community pharmacists as peripheral professionals}

Pharmacists continue to press their case to be more closely involved in the provision of community health care (Harding and Taylor 1997). In our study, administering and controlling medication supplies, and encouraging and monitoring adherence to prescriptions, were activities which workers (and nurses in particular) routinely undertook across both sites, reflecting the general importance attached to medication work in mental health care (Gournay 2005). In Jim's case, for example, protracted negotiations centered on managing his tablet supply, underpinned by the idea that erratic use of medicines had contributed to his trajectory spinning out of control (and Jim entering hospital) prior to his formal involvement in the study. As his community nurse put it:

Community nurse: The biggest problem with Jim is his compliance with medication. That's always been the issue with Jim and once he does start non-complying then he deteriorates very, very quickly and so basically it's, I'm really looking for signs of relapse with Jim, and with Jim they are very clear cut. (Interview, community nurse, PD2).

In Kerry's case, a particular concern of professionals was her access to stored insulin which could be used in a future suicide attempt, as the psychiatrist involved in her care indicated: 
Psychiatrist: Her risk of self-harm is quite high, and in addition to that she has the means to do it in as much as she has insulin, and that in itself is problematic because her monitoring for her diabetes is very poor, so she's a risk. (Interview, psychiatrist, PD71).

Negotiations between mental health and primary care staff, and with Kerry directly, were opened in this context with the aim of adjusting Kerry's insulin prescription and simultaneously retrieving stored supplies:

Community nurse: I seem to fax the GP [general medical practitioner] quite a bit, trying to sort the medication out. Kerry gets a bit chaotic, all the, not all the time, oh they screw it up their end, the medication goes awry. Tamsin's [Kerry's psychiatrist] actually written now to the GP, this is just in hindsight, the other day, because Kerry's stockpiling insulin so I'm going round to get it later. (Interview, community nurse, PD73).

Despite the centrality of medications storage and adherence in these cases, the actual and potential contribution of pharmacists was largely invisible to other paid workers (just as, as While et al. (2005) note, pharmacists tend to be ignored in studies of health and social care work). Where other members of Kerry's network of paid carers engaged in frequent interactions the pharmacist usually dispensing mental health medicines to Kerry described her contact with mental health workers as being limited to her initiating calls to a psychiatrist to request corrections to poorly prepared prescriptions. She also described herself as only recently becoming aware of Kerry's insulin therapy, suggesting Kerry's use of more than one pharmacy outlet (and therefore highlighting a system feature militating against individual pharmacists' ongoing involvement). Kerry's usual dispensing pharmacist recognized her role as being on the periphery, linking this to her occupational group's distinctive position within the division of labor in which professional work is typically combined with running (or working in) private businesses (Edmunds and Calnan 2001):

Community pharmacist: They [other health and social care workers] think we're shopkeepers, they still think we're shopkeepers. We do dispense prescriptions but basically we're shopkeepers who are in it to make money, it's just, and we haven't got a professional side. (Interview, community pharmacist, PD90). 
In Jim's case, community pharmacist involvement in the preparation and dispensing of medicines was ongoing and consistent, but was neither negotiated nor integrated with other elements of Jim's care. Each week, the same pharmacist physically prepared Jim's drugs. Blister packs were used to divide up medicines into daily doses, in an attempt to promote concordance. After preparation, Jim's tablets were transported directly to his home, as part of a service provided to all regular users of this pharmacy whose disabilities made personal collection difficult. The pharmacist attached to this business described engaging in negotiations initiated by Jim's principal lay carer (in the past this neighbor had, for example, been the person to alert the pharmacist of Jim's return home from hospital and the consequent need to restart home medication deliveries), but having no significant interactions with members of Jim's network of paid mental health carers:

Researcher: Do you have any contact at all with, I mean you mentioned the GP, a receptionist there, do you have contact at all with the community mental health team?

Community pharmacist: No.

Researcher: What are the implications of that, if any?

Community pharmacist: Well, basically if they change his medication, if they've forgotten to tell the GP and I don't know either then nothing's going to get changed [...] it's like a double check system but obviously it's not in place because they don't liaise with me at all. (Interview, community pharmacist, PD10).

Support workers as providers of practical but undervalued care

The contributions of support workers are often vital in the care of people living with long-term mental health problems in the community (Murray et al. 1997). Paid non-professional staff in this study had high levels of face-to-face contact with service user participants, and fulfilled roles which had a clear focus on day-to-day practicalities. In Jenny's case, for example, a nursing assistant was enrolled into her network of care to help with daily activities: 
Nursing assistant: On a Friday, every Friday morning, nice and early we go to the butchers, she buys all her meat for the week and then we go round to the fruit and veg shop where she gets all her fruit and veg. (Interview, nursing assistant, PD87).

In Jim's case a nursing assistant was enlisted to help with a wide range of tasks, some of which were directly health-related whilst others were not. All, however, were important in sustaining Jim in his own home:

Nursing assistant: Since my involvement with Jim I've accompanied him to MIND Advocacy [a non-statutory sector service], 'cause he received a letter and he wanted to know a bit more about it, so we went there and I've also been involved with, he needed new windows and doors which was a little bit distressing for him and he needed some reassurance with regards to when they were coming, so we went to the housing association. Also as well, if he has any hospital appointments I'm to accompany him, accompany him to there to just clarify treatment plans really and also add support 'cause, you know, going to hospital and things can be a bit overwhelming can't they, for everybody. (Interview, nursing assistant, PD29).

In Kerry's case, financial support from the local authority helped secure the services of an independent sector support worker whose formal role centered on practical activities such as shopping and cooking, but which over time had naturally extended to include the provision of informal interpersonal support:

Support worker: [...] my role was to come in and help Kerry with her shopping [... ] I've been seeing Kerry for over two years, even though she knows I'm a support worker, you do build up a friendship. You can't, I mean I'm not made of stone, at the end of the day. (Interview, support worker, PD81).

Support workers lacking membership of professionalized groups, however, can find themselves both undervalued and relatively invisible to others working in the community mental health field (Onyett et al. 1995). Whilst fulfilling significant practical and socially supportive roles and thus contributing to the stabilization of trajectories, paid non-professionals in this context were liable to be excluded from events where decisions were being made and where their knowledge might have been usefully shared. This had consequences in Simon's case. His was a closely managed trajectory, with a clear goal. Part of his routine (up to four times each week) was to participate in rehabilitative activities at a local 
authority day service in preparation for his move to more independent living. The day service worker who knew Simon best described this work as helping Simon develop skills crucial to everyday living in the community, including budgeting, food shopping and storage, and cooking. When it came to pooling information about Simon's progress and negotiating plans for his future, however, day center staff were conspicuous by their absence at both the face-to-face care planning meetings held for Simon which were observed during fieldwork:

Researcher: Were you invited to the section $117^{2}$ meeting with Simon which was a couple of weeks, two or three weeks ago?

Day service worker: No we weren't. We used to be, and anything, any review that went on at The Oaks [the residential home Simon lived in] we used to go there.

Researcher: Go there as well, right. Used to. Because they had one of those for Simon as well about four or five weeks ago.

Day service worker: That's right. Which was quite productive as far as I'm concerned on both sides for them and for us, you know, because I could be going over things with Simon that he's actually doing you know [...]. (Interview, day center worker, PD22).

The absence of this support worker at care planning events meant that important opportunities were thus missed to negotiate Simon's longer-term resettlement in a context where knowledge of his daily living skills could be shared.

Lay carers: contrasting modes of involvement

The work of unpaid carers in the support of adults with mental health problems living in the community, other than in the case of care for older people with dementia, is particularly invisible (Twigg and Atkin 1994). This work can be both demanding and stigmatizing, and is undertaken in a context in which families are sometimes made to feel responsible for their loved ones' difficulties (Perkins and Repper 1996). Across these six trajectories dramatically contrasting modes of

\footnotetext{
${ }^{2}$ Section 117 refers to the provision of statutory aftercare for people who have been subject to treatment sections of the Mental Health Act for England and Wales.
} 
involvement were exemplified. Simon, who until a year before participating in the study had been a user of secure inpatient forensic mental health services, received no care from family members or other unpaid workers. As his social worker put it:

Social worker: $[\ldots]$ his family made it quite clear when he was in the private hospital that they no longer wanted any contact with him, they'd just had enough over the years, which is a shame because he's actually better now than he has been.

Researcher: Yes. Yes, he might not be the person they remembered.

Social worker: No. But they'd just had enough and Simon made a number of attempts to contact them. I think he wrote some letters that the social workers in the private hospital helped him with, but I'm not sure whether he even received a response from his family. (Interview, social worker, PD23).

In this context, Simon's needs were necessarily met solely by workers employed by health and social care agencies. In contrast, Jim's network of care exemplifies the active (if unrecognized) contribution that unpaid carers sometimes make in the support of people with mental health problems living in community settings. Jim was well-known in his locality, and was a man whose age and combination of physical and mental health problems marked him as being particularly vulnerable. Members of his local community (not his kin) played an essential part in sustaining Jim in his own home, with a key role being played by a neighbor. Her involvement, according to Jim's community nurse, had evolved over a seven year period to become increasingly significant:

Community nurse: I think she just befriended him [Jim] initially. When she moved to the current premises, which is two doors away, and he sort of popped in to say 'hello' to the new neighbor really, and then he sort of, what he does every morning, he goes in, he makes them, the two ladies there, Sarah [principal lay carer], and makes them a cup of coffee and takes them in and so they sort of just got to, well they got to befriend him really and sort of keeping an eye on him. (Interview, community nurse, PD2).

Proximity and willingness to help meant that the tasks attached to Jim's neighbor had expanded over time. Paid workers recognized the importance of this lay work, with both Jim's GP and his psychiatrist drawing attention during interviews to the value of these informal contributions. Jim's nurse/care 
coordinator, too, acknowledged that without the practical support of members of his community Jim would have needed significantly increased, paid-for, services. As principal, involved, professional he actively engaged in purposeful, work-oriented, interactions with Jim's neighbor. These assumed particular significance in the context of managing Jim's transition home from hospital, and on the initiative of the neighbor led to a brokering of a direct lay carer role in supervising Jim's tablets. As she put it:

Researcher: So whose idea was it for you to have the tablets, for him [Jim] to have them from you four times every day?

Lay carer: Well, I think, I think he came in, he came home this time, didn't he, with them all in a packet, all separated like that. Because I have to be fair, he'd go down the doctor's for his prescription and he'd come up with a bag full of bottles and what have you, he couldn't understand them. Some of them would say 'as directed', so I'd have to phone them to say, 'what does 'as directed' mean?' Then he'd have to put it in big black ink, 'one time a day', 'three times a day' and all of that. So I think that wasn't helping him, it was too much for him to deal with that was. So this time now when he came in with the packet as they do, well I suggested then, I said, 'well, I can manage that', you know, and, 'if you let me have them here, all well and good, see'. (Interview, lay carer, PD3).

Close contact with Jim over a period of years meant that this main lay carer had also developed valuable knowledge of the early warning signs associated with deteriorations in Jim's mental health. This had proved significant during the phase of Jim's trajectory ending in his hospital admission, with unpaid carers being the first to notice a worsening in his mental health. Like support workers, however, lay carers were a relatively invisible group when information was being pooled and decisions made, a finding echoing Allen's (2000) that professionals can find it difficult to involve expert carers in ways which do not threaten their sense of competence. In Jim's case during the trajectory phase leading to his hospital admission, members of his community were able to trigger a professional response only after a careful 'staging' of actions (Levy 1982) in which, his neighbor said, multiple concerned lay people organized sequences of calls to the community mental health team to share their concerns over Jim's deterioration. 
Service user work: 'good' and 'bad' patients

One of Strauss and his colleagues' most insightful observations in their writing on trajectories is to recognize the work of patients (Strauss et al. 1985). They add that 'patient work' can be considered in a number of ways, including the degree to which this is judged by others as legitimate. Legitimate work, from the viewpoint of paid personnel, is what 'good patients' do in the service of better managing their trajectories. Miriam, for example, was independently described by her nurse, GP and her social worker as being a 'good patient' in this way. Her work included keeping appointments, adhering to prescribed medicines, and initiating and maintaining additional contact with paid carers during problematic phases of her trajectory. Her interpretations of the nature of her ill-health were also consistent with those held by her paid carers. Even though Miriam's unfolding trajectory was one of the most complicated encountered during fieldwork she was, then, also perceived by workers as fulfilling the role expected of her and could not, therefore, be held responsible for her episodic crises. Her primary care doctor said:

GP: No, she's one of those patients who, quite honestly, the hospital clinics, outpatients, psychiatric clinics monitor very well and when she is admitted she responds very quickly and she goes home able to cope. I would be concerned and I would become more involved if she came home and wasn't coping but she's a model patient in that point of view. She does respond to medication, she does take her medication. (Interview, general practitioner, PD67).

Not all of the case study subjects were perceived in this way. Being a 'difficult' person in a mental health system context can mean doing things which challenge practitioner control and competence (Breeze and Repper 1998), and which run counter to professional ideas of what should be done to recover from (or adjust to) illness or to stabilize a wayward trajectory. Lenny, for example, had failed to fit comfortably into neat diagnostic boxes or (during past trajectory phases) to 'get better'. In this context, review of professional workers' written records revealed the extent to which he had historically participated in a very inconsistent mental health service punctuated by repeated discharges, re-referrals and missed appointments. Kerry, who during fieldwork visits was observed resisting engaging in tasks (such as relinquishing supplies of insulin) requested of her by professionals was described as 'manipulative' by a nurse:

Nurse: $[\ldots]$ she's very manipulative and there were sort of lots of suicide threats all the time and stuff like that. [...] the diagnosis is partly schizophrenia and partly borderline personality 
disorder and it's because of that personality disorder, she's, you know, quite manipulative. (Interview, community nurse, PD73).

Nothing in our data suggests that Kerry’s care was compromised in this context, though this interview extract indicates a willingness to evaluate service users' differing modes of engagement in ways which carry moral overtones.

\section{Discussion}

Here we have shown how trajectories unfolding in the community mental health field are both complex and dynamic. We have also demonstrated how workers can become attached to 'bundles of tasks' (Hughes 1971) which bear little relation to their place in a formal division of labor, underscoring the idea that, at their core, roles are accomplished through interaction (Freidson 1976). The contribution of Jim's neighbor and main lay carer is particularly revealing in this regard. Nothing in her role was formally prescribed or could be taken-for-granted, and yet over time and through negotiated processes her work had grown to a position of significance. Hughes (1971) also draws important distinctions between tasks and social roles, and observes how different types of work are accorded different status. Trajectories would have been vulnerable to moving out of kilter, and care becoming considerably more costly for some, without the work of non-professionals in managing budgets, shopping, cooking and generally providing help. Yet the significance of these activities did little to raise the profile of the lay carers and support workers doing them, leading us to speculate how, from the perspective of some

professionals, certain types of contribution may be seen as important but nonetheless 'dirty' (Emerson and Pollner 1976) and therefore better left to relatively invisible others. We have also shown how professionals can differentially evaluate service users based on their degrees of cooperation with preferred plans of care.

Our findings have particular value for policymakers, managers, practitioners and others who share concerns with the individual-level organization of mental health care. These readers, and others equally knowledgeable of mental health systems and services, will draw their own conclusions regarding the typicality of the people and events described, but in our estimation nothing about the six service users or their caring networks marks them out as spectacularly unusual. Without in any way 
underestimating the meaning and significance of each trajectory from the perspective of those intimately involved, each can thus be viewed as broadly typical of others, and therefore worth generalizing from. The extent to which all six trajectories were in motion, and simultaneously drew on the dispersed contributions of a wide range of paid and unpaid workers, points to the vital importance of what Strauss et al. (1985) call 'articulation work'. Work of this type is concerned with the coordination of collective effort, and the shaping of trajectories lest each becomes what Strauss and his colleagues (1985: 160-181) refer to as a 'cumulative mess'. In many mental health systems around the world articulation work is bound up within processes of case management (Onyett 1998). In the UK, for example, the importance of care coordination is recognized in the policy of the care program approach (CPA) (Welsh Assembly Government 2003; Department of Health 2008). For each user of mental health services this requires the identification of a single professional with ongoing responsibilities to ensure that needs are assessed, care is planned and provided, and that all contributions are pulled together. Whilst the bureaucracy associated with the CPA can make it difficult for practitioners to also engage in therapeutic activities (Simpson 2005) our data illustrate precisely why it is that work of this type needs to be done. Articulation is necessary because mental health work is 'people work', and because trajectories are vulnerable to being thrown off course. It is also needed because contributions to care are made by a surprising variety of people, including those whose work is often invisible and those whose activities challenge professional competence. In the light of these observations we suggest that care coordination may be best undertaken by practitioners combining organizational capabilities with the interactional skills needed to forge helpful and productive relationships with all workers, paid and unpaid, involved in any given case. 


\section{References}

Allen, D. (2000). Negotiating the role of expert carers on an adult hospital ward. Sociology of Health and Illness, 22(2), 149-171.

Allen, D., Griffiths, L., \& Lyne, P. (2004). Understanding complex trajectories in health and social care provision. Sociology of Health and Illness, 26(7), 1008-1030.

Ayres, L., Kavanaugh, K., \& Knafl, K.A. (2003). Within-case and across-case approaches to qualitative data analysis. Qualitative Health Research, 13(6), 871-883.

Bowers, L. (1992). Ethnomethodology II: a study of the community psychiatric nurse in the patient's home. International Journal of Nursing Studies, 29(1), 69-79.

Breeze, J.A., \& Repper, J. (1998). Struggling for control: the care experiences of 'difficult' patients in mental health services. Journal of Advanced Nursing, 28(6), 1301-1311.

Brown, B., \& Crawford, P. (2003). The clinical governance of the soul: 'deep management' and the self-regulating subject in integrated community mental health teams. Social Science \& Medicine, $56(1), 67-81$.

Brown, B., Crawford, P., \& Darongkamas, J. (2000). Blurred roles and permeable boundaries: the experience of multidisciplinary working in community mental health. Health and Social Care in the Community, 8(6), 425-435.

Coffey, A., \& Atkinson, P. (1996). Making sense of qualitative data: complementary research strategies. London: Sage.

Coleman, J.S. (1958). Relational analysis: the study of social organizations with survey methods. Human Organization, 16(4), 28-36.

Corbin, J.M., \& Strauss, A.L. (1988). Unending work and care: managing chronic illness at home. San Francisco: Jossey-Bass.

Crawford, P., Brown, B., \& Majomi, P. (2008). Professional identity in community mental health nursing: a thematic analysis. International Journal of Nursing Studies, 45(7), 1055-1063. 
Department of Health. (2008). Refocusing the care programme approach: policy and positive practice guidance. London: Department of Health.

Edmunds, J., \& Calnan, M.W. (2001). The reprofessionalisation of community pharmacy? An exploration of attitudes to extended roles for community pharmacists amongst pharmacists and general practitioners in the United Kingdom. Social Science \& Medicine, 53(7), 943-955.

Emerson, R., \& Pollner, M. (1976). Dirty work designations: their features and consequences in a psychiatric setting. Social Problems, 23(3), 243-254.

Freidson, E. (1976). The division of labor as social interaction. Social Problems, 23(3), 304-313.

Godin, P. (1996). The development of community psychiatric nursing: a professional project? Journal of Advanced Nursing, 23(5), 925-934.

Gournay, K. (2005). The changing face of psychiatric nursing. Advances in Psychiatric Treatment, 11(1), 6-11.

Hannigan, B., \& Allen, D. (2003). A tale of two studies: research governance issues arising from two ethnographic investigations into the organisation of health and social care. International Journal of Nursing Studies, 40(7), 685-695.

Hannigan, B., \& Allen, D. (2006). Complexity and change in the United Kingdom's system of mental health care. Social Theory \& Health, 4(3), 244-263.

Hannigan, B., \& Allen, D. (2011). Giving a fig about roles: policy, context and work in community mental health care. Journal of Psychiatric and Mental Health Nursing, 18(1), 1-8.

Harding, G., \& Taylor, K. (1997). Responding to change: the case of community pharmacy in Great Britain. Sociology of Health and Illness, 19(5), 547-560.

Hart, E. (2001). System induced setbacks in stroke recovery. Sociology of Health and Illness, 23(1), 101-123.

Hughes, E. (1971). The sociological eye: selected papers on work, self and the study of society. Chicago: Aldine. 
Levy, J.A. (1982). The staging of negotiations between hospice and medical institutions. Urban Life, 11(3), 293-311.

Lewins, A., \& Silver, C. (2007). Using software in qualitative research: a step-by-step guide. London: Sage.

Morrall, P.A. (1997). Professionalism and community psychiatric nursing: a case study of four mental health teams. Journal of Advanced Nursing, 25(6), 1133-1137.

Murray, A., Shepherd, G., Onyett, S., \& Muijen, M. (1997). More than a friend. The role of support workers in community mental health services. London: The Sainsbury Centre for Mental Health.

Norman, I.J., \& Peck, E. (1999). Working together in adult community mental health services: an interprofessional dialogue. Journal of Mental Health, 8(3), 217-230.

Onyett, S. (1998). Case management in mental health. Cheltenham: Stanley Thornes.

Onyett, S., Pillinger, T., \& Muijen, M. (1995). Making community mental health teams work: CMHTs and the people who work in them. London: The Sainsbury Centre for Mental Health.

Peck, E., \& Norman, I.J. (1999). Working together in adult community mental health services: exploring interprofessional role relations. Journal of Mental Health, 8(3), 231-242.

Perkins, R., \& Repper, J. (1996). Working alongside people with long term mental health problems. London: Chapman and Hall.

Pollock, L.C. (1989). Community psychiatric nursing: myth and reality. Harrow: Scutari.

Scientific Software Development. (2009). Atlas.ti: the knowledge workbench (version 5.5). Berlin: Scientific Software Development.

Sheppard, M. (1991). Mental health work in the community: theory and practice in social work and community psychiatric nursing. London: Falmer.

Simpson, A. (2005). Community psychiatric nurses and the care coordinator role: squeezed to provide 'limited nursing'. Journal of Advanced Nursing, 52(6), 689-699. 
Sladden, S. (1979). Psychiatric nursing in the community: a study of a working situation. Edinburgh: Churchill Livingstone.

Stark, S., Stronach, I., \& Warne, T. (2002). Teamwork in mental health: rhetoric and reality. Journal of Psychiatric and Mental Health Nursing, 9(4), 411-418.

Strauss, A., Fagerhaugh, S., Suczek, B., \& Wiener, C. (1985). Social organization of medical work. Chicago: University of Chicago Press.

Twigg, J., \& Atkin, K. (1994). Carers perceived: policy and practice in informal care. Maidenhead: Open University Press.

Welsh Assembly Government. (2003). Mental health policy guidance: the care programme approach for mental health service users. Cardiff: Welsh Assembly Government.

While, A., Shah, R., \& Nathan, A. (2005). Interdisciplinary working between community pharmacists and community nurses: the views of community pharmacists. Journal of Interprofessional Care, 19(2), 164-170.

Wooff, K., \& Goldberg, D.P. (1988). Further observations on the practice of community care in Salford: differences between community psychiatric nurses and mental health social workers. British Journal of Psychiatry, 153(1), 30-37.

Wooff, K., Goldberg, D.P., \& Fryers, T. (1988). The practice of community psychiatric nursing and mental health social work in Salford: some implications for community care. British Journal of Psychiatry, 152(6), 783-792.

Yin, R.K. (2009). Case study research: design and methods (4th ed.). London: Sage. 